51 Kopelman M, Fleminger S. Experience and perspectives on the classification of organic mental disorders. Psychopathology 2002; 35: 76-81.

52 Hasin D, Harzenbuehler M, Keyes K, Ogburn E. Substance use disorders: Diagnostic and Statistical Manual of Mental Disorders, fourth edition (DSMIV) and International Classification of Diseases, tenth edition (ICD-10). Addiction 2006; 101 (suppl 1): 59-75.

53 Rounsaville B. Experience with ICD-10/DSM-IV substance use disorders. Psychopathology 2002; 35: 82-8.

54 Bertelsen A. Schizophrenia and related disorders: experience with current diagnostic systems. Psychopathology 2002; 35: 89-93.

55 Paykel E. Mood disorders: review of current diagnostic systems. Psychopathology 2002; 35: 94-9.

56 Cassidy F, Yatham L, Berk M, Grof P. Pure and mixed manic subtypes: a review of diagnostic classification and validation. Bipolar Disord 2008; 10 131-43

57 Cookson J. Toward a clinical understanding of bipolar disorders: classification and presentation. Epilepsia 2005; 45 (suppl 4): 3-7.

58 Lopez-Ibor J, Frances A, Jones C. Dysthymic disorder: a comparison of DSM-IV and ICD-10 and issues in differential diagnosis. Acta Psychiatr Scand Suppl 1994; 383: 12-8.

59 Lopez-Ibor J. The classification of stress-related disorders in ICD-10 and DSM-IV. Psychopathology 2002; 35: 107-11.

60 Hatzimouraticix K, Hatzichristou D. Sexual dysfunctions: classifications and definitions. J Sex Med 2007; 4: 241-50.
61 Vroege J, Gijs L, Hengeveld M. Classification of sexual dysfunctions: towards DSM-V and ICD-11. Compr Psychiatry 1998; 39: 333-7.

62 World Health Organization. The ICD-10 Classification of Mental and Behavioural Disorders: Diagnostic Criteria for Research. WHO, 1993.

63 Kendell R. The relationship between DSM-IV and ICD-10. J Abnorm Psychol 1991; 100: 297-301.

64 Widiger T, Simonsen E, Sirovatka P, Regier D. Dimensional Models of Personality Disorders: Refining the Research Agenda for DSM-V. American Psychiatric Association, 2007.

65 Saunders J, Schuckit M, Sirovatka P, Regier D. Diagnostic Issues in Substance Use Disorders. Refining the Research Agenda for DSM-V. American Psychiatric Association, 2007.

66 Bertelsen A. Wanted: validation studies on the current diagnostic classifications. Acta Psychiatr Scand 2002; 106: 81-2.

67 Kessing LV. Severity of depressive episodes according to ICD-10: prediction of risk of relapse and suicide. Br J Psychiatry 2004; 184: 153-6.

68 Cooper J. Prospects for Chapter V of ICD-11 and DSM-V. Br J Psychiatry 2003; 183: 379-81.

69 World Health Organization. The Sixth Revision of the International Statistical Classification of Diseases, Injuries and Causes of Death (ICD-6). WHO, 1948.

70 Sussman N. In Session with Darrel A. Regier, MD, MPH: The Developmental Process for the Diagnostic and Statistical Manual of Mental Disorders, Fifth Edition. Prim Psychiatry 2007; 14: 44-7.

\title{
The electroshock riddle: effective but rejected
}

\section{Max Fink}

Full remission of a psychiatric illness is rare. For marketing approval of a medicine we accept a $50 \%$ reduction in symptoms as statistically better than the $40 \%$ reported with placebo. By contrast, the electroshock experience has greater than $80 \%$ remission rates in melancholia, mania and catatonia. Yet electroshock is disparaged and legislated against. Many reasons are given. Fear of electricity. Abandonment by psychiatrists of a hands-on experience in office-based practices. Antagonism by psychotherapists, psychologists, Scientologists and former patients. All of the above? Physicians have induced seizures effectively and safely for 75 years. Is it not time to change our attitude? 